\title{
Rotational Vertebral Artery Occlusion Mechanisms and Long-term Outcome
}

\author{
Kwang-Dong Choi, MD*; Jae-Hwan Choi, MD*; Ji-Soo Kim, MD; Hyo Jung Kim, MSc; Min-Ji Kim, BSc; \\ Tae-Hong Lee, MD; Hyung Lee, MD; In Soo Moon, MD; Hui Jong Oh, MD; Jae-Il Kim, MD
}

Background and Purpose - To elucidate the mechanisms and prognosis of rotational vertebral artery occlusion (RVAO).

Methods - We analyzed clinical and radiological characteristics, patterns of induced nystagmus, and outcome in 21 patients (13 men, aged 29-77 years) with RVAO documented by dynamic cerebral angiography during an 8-year period at 3 University Hospitals in Korea. The follow-up periods ranged from 5 to 91 months (median, 37.5 months). Most patients $(\mathrm{n}=19 ; 90.5 \%)$ received conservative treatments.

Results - All the patients developed vertigo accompanied by tinnitus (38\%), fainting (24\%), or blurred vision (19\%). Only $12(57.1 \%)$ patients showed the typical pattern of RVAO during dynamic cerebral angiography, a compression of the dominant vertebral artery at the C1-2 level during contralateral head rotation. The induced nystagmus was mostly downbeat with horizontal and torsional components beating toward the compressed vertebral artery side. None of the patients with conservative treatments developed posterior circulation stroke, and 4 of them (21.1\%) showed resolution of symptoms during the follow-ups.

Conclusions-RVAO has various patterns of vertebral artery compression, and favorable long-term outcome with conservative treatments. In most patients with RVAO, the symptoms may be ascribed to asymmetrical excitation of the bilateral labyrinth induced by transient ischemia or by disinhibition from inferior cerebellar hypoperfusion. Conservative management might be considered as the first-line treatment of RVAO. (Stroke. 2013;44:1817-1824.)

Key Words: mechanism $\boldsymbol{\square}$ prognosis $\boldsymbol{\square}$ rotational vertebral artery occlusion $\boldsymbol{\square}$ stroke

$\mathrm{R}_{\mathrm{i}}$ otational vertebral artery occlusion (RVAO) is characterized by recurrent attacks of paroxysmal vertigo, nystagmus, and syncope induced by horizontal head rotation. ${ }^{1-3}$

Most patients with RVAO exhibit a stenosis or anomaly (eg, hypoplasia or termination in the posterior inferior cerebellar artery) of the vertebral artery (VA) on 1 side and the dominant VA is compressed at the C1-2 level during contraversive head rotation, which compromises the blood flow in the vertebrobasilar artery territory (typical RVAO; Figure 1). ${ }^{3-5}$ However, some patients may show atypical patterns, such as compression of VA at other cervical levels, ${ }^{6-11}$ simultaneous compression of both VAs, ${ }^{2,12-15}$ compression of the dominant VA during ipsilateral head rotation or tilt, ,7,10,11,16 and compression of the nondominant VA terminating in the posterior inferior cerebellar artery (PICA). ${ }^{17-19}$ Based on the side of tinnitus and patterns of nystagmus induced by head rotation, transient excitation of the inner ear in the compressed VA side has been proposed as a mechanism of vertigo and nystagmus in RVAO., ${ }^{3,20-22}$ In contrast, transient ischemia of the inferior cerebellum or lateral medulla rather than labyrinth may induce isolated vertigo and nystagmus in RVAO ${ }^{19}$ Because previous reports on RVAO are mostly limited to anecdotal case reports, anatomic characteristics and underlying mechanisms of vertigo and nystagmus require further exploration in RVAO.

Conservative, surgical, and more recently endovascular intervention have been proposed as treatment options of RVAO. $^{2,23-27}$ Because a previous review of published cases revealed that $\approx 50 \%$ of patients with conservative treatments developed stroke with permanent neurological deficits, ${ }^{2}$ surgical decompression has generally been recommended in patients with RVAO. However, long-term outcome of conservative treatment remains to be elucidated in RVAO.

We report clinical and radiological characteristics, patterns of nystagmus, and long-term outcome of 21 patients with RVAO documented by dynamic cerebral angiography $>8$-year period at 3 University Hospitals in Korea.

Received February 27, 2013; final revision received March 27, 2013; accepted March 29, 2013.

From the Departments of Neurology (K.-D.C.,M.-J.K.) and Radiology (T.-H.L.), Pusan National University Hospital, Pusan National University School of Medicine and Biomedical Research Institute, Busan, South Korea; Department of Neurology, Pusan National University Yangsan Hospital, Pusan National University School of Medicine and Biomedical Research Institute, Yangsan, South Korea (J.-H.C.); Department of Neurology, Seoul National University College of Medicine, Seoul National University Bundang Hospital, Seongnam, South Korea (J.-S.K., H.J.K.); Department of Neurology, Keimyung University School of Medicine, Daegu, South Korea (H.L.); Department of Neurology, Daedong Hospital, Busan, South Korea (I.S.M.); MTV (Migraine, Tinnitus, and Vertigo) Clinic, Oh Neurology Center, Daegu, South Korea (H.J.O.); and Department of Neurology, Dankook University College of Medicine, Cheonan, South Korea (J.-I.K.).

*Drs K.-D. Choi and J.-H. Choi contributed equally to this article.

Correspondence to Ji-Soo Kim, MD, PhD, Department of Neurology, Seoul National University College of Medicine, Seoul National University Bundang Hospital, 300 Gumi-dong, Bundang-gu, Seongnam, Gyeonggi-do 463-707, South Korea. E-mail jisookim@ snu.ac.kr

(C) 2013 American Heart Association, Inc. 
A

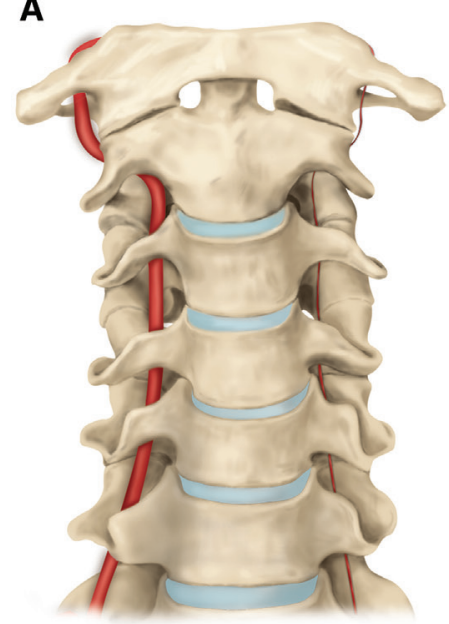

B

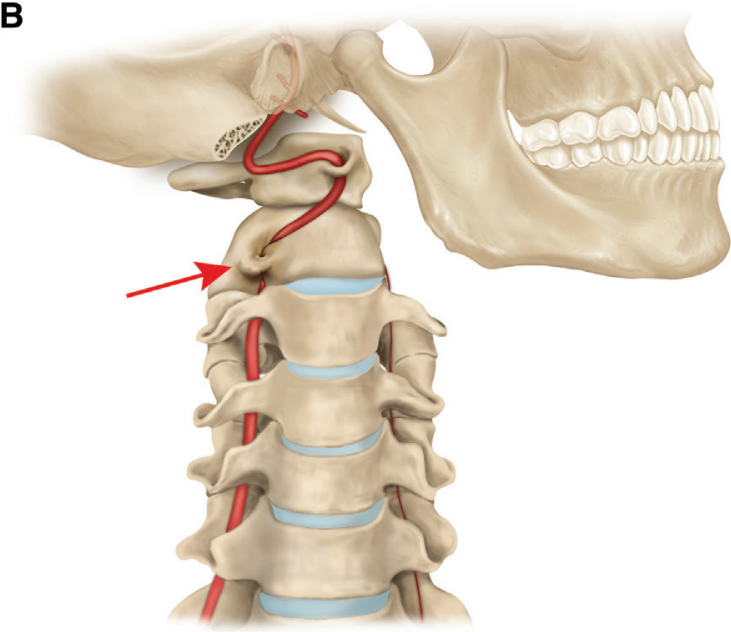

Figure 1. Typical rotational vertebral artery occlusion. A typical pattern of rotational vertebral artery occlusion shows a stenosis or anomaly of the vertebral artery on 1 side $(\mathbf{A})$ and compression of the dominant vertebral artery at the C1-2 level during contraversive head rotation $(\mathbf{B})$.

\section{Methods}

\section{Subjects}

We initially recruited 23 patients with RVAO at 3 Neurology Clinics of University Hospitals in Korea from April 2004 to September 2012. After excluding 2 patients who did not have dynamic angiography, 21 patients with RVAO were finally enrolled. All patients had full neurological and neuro-otologic evaluation by the authors. All patients developed paroxysmal vertigo in the rotated or tilted head position because of compression of VA, which was confirmed by dynamic conventional or computerized tomography (CT) angiography. Data of the 21 patients were collected from each clinic using a structured registration form that included demographic and clinical features, the results of radiological evaluation, and prognosis. The patients included 13 men with the age ranging from 29 to 77 years (mean \pm SD, $58.7 \pm 13.5$ years). The follow-up durations ranged from 5 to 91 months (39.9 \pm 27.0 months; median, 37.5 months). Eight patients (patients $2-5,10,16,20$, and 21 ) were previously reported, but included in this study for completeness of the data. 16,19,20,22

All experiments followed the tenets of the Declaration of Helsinki, and the institutional review boards of all participating hospitals (Pusan National University Hospital, Seoul National University Bundang Hospital, and Keimyung University School of Medicine) approved this study.

\section{Oculographic Study}

Eye movements were recorded binocularly at a sampling rate of 60 $\mathrm{Hz}$ using 3-dimensional (3D) video-oculography (SensoMotoric Instruments, Teltow, Germany) in 20 of 21 patients, whereas those were observed on a monitor using video goggles (SLMED, Seoul, Korea) in the remaining 1 patient.

In a seated position, spontaneous nystagmus was recorded both with and without fixation in the primary position. For positional nystagmus, patients bent down, straightened, and turned their heads to either side while supine. Patients were moved from a supine to a sitting position, and the head was turned to either side. Patients were also subjected to Dix-Hallpike maneuvers and the straight head hanging test. In 1 patient (patient 21) with a history of vertigo during head tilt, eye movements were also recorded during head tilt to either side while sitting.

\section{Radiological Evaluation}

All patients had imaging of the brain with MRI and MR angiography, and conventional or CT angiography in the standard position (anterior-posterior and lateral) and during head rotation or tilt to either side. CT of the cervical spine was also performed to identify any bony abnormality that may compress the VA in all patients.

\section{Treatments}

Most patients ( $n=19 ; 90.5 \%)$ received conservative treatments with antiplatelet agents and instructions to avoid prolonged head rotation or tilt, whereas the remaining 2 (patients 2 and 7) had fusion of the cervical spines.

\section{Results}

\section{Clinical Characteristics}

Rotatory vertigo developed in all patients during head rotation to $1(n=19)$ or both sides $(n=1)$, or head tilt to 1 side $(n=1$; Figure 2; Table 1). The vertigo immediately resolved in all when the patients resumed the neutral head position. Eight patients (38\%) also had tinnitus along with the vertigo. Four of them reported tinnitus in both ears, whereas the others noticed tinnitus in the ear of the compressed VA side $(n=3)$ or in the opposite side $(n=1)$. The tinnitus developed simultaneously or several seconds after the onset of vertigo and nystagmus in 7 patients, but it occurred in the ear of the compressed VA side on resuming the neutral head position in the remaining patient (patient 9). Five patients (24\%) developed fainting for a few seconds, and 4 (19\%) had blurred vision during head rotation or tilt. Four patients (19\%) developed nausea or vomiting with the vertigo.

\section{Patterns and Levels of VA Compression}

All patients showed compression of VA during horizontal head rotation to $1(n=19)$ or both sides $(n=1)$ or during head tilt to 1 side $(n=1$; Table 1$)$. Twelve $(57.1 \%)$ of them exhibited the typical pattern of RVAO, which is characterized by compression of the dominant VA at the C1-2 level during contralateral head rotation (Figure 1).

The remaining 9 patients showed (1) patent bilateral VAs and simultaneous compression of the VAs during head 


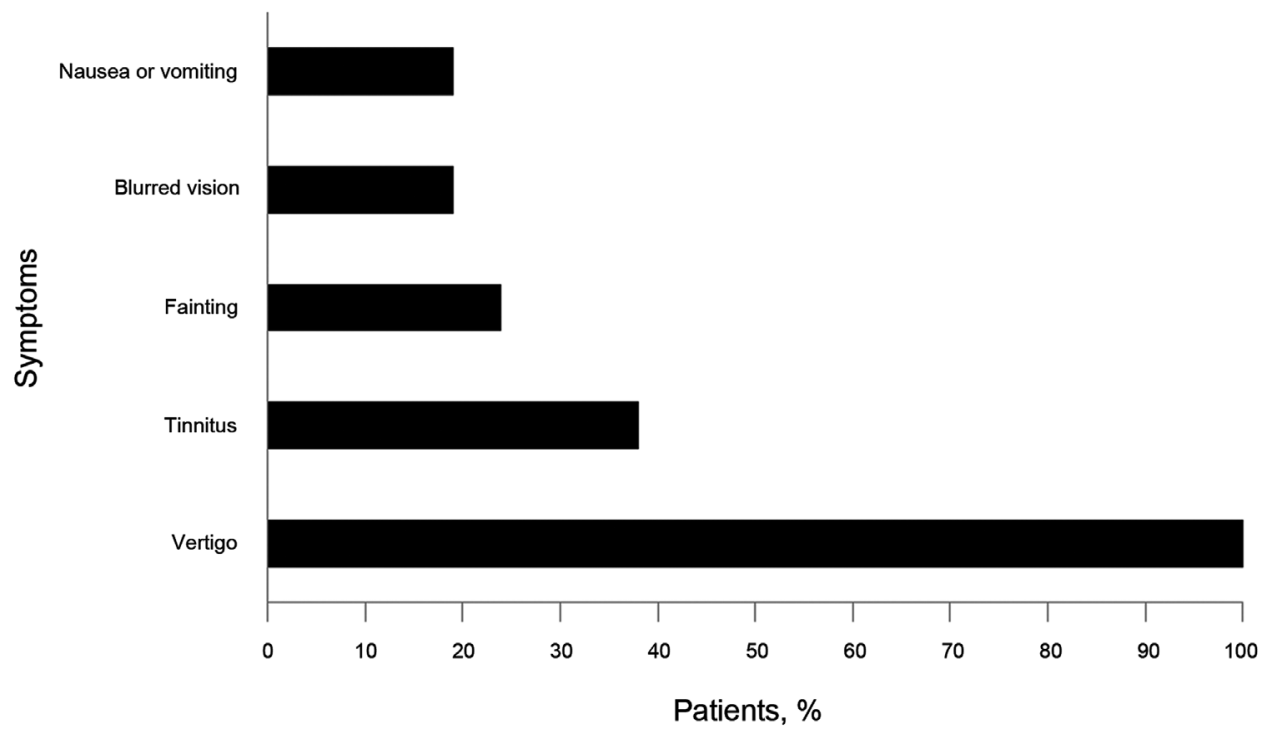

Figure 2. Accompanied symptoms in 21 patients with rotational vertebral artery occlusion.

rotation to 1 side at the $\mathrm{C} 6$ level in the ipsiversive VA and at the $\mathrm{C} 1-2$ level in the contraversive VA $(n=2$; patients 13 and 14; Figure 3A); (2) patent bilateral VAs and compression of the either VA at the C1-2 level during contraversive head rotation $(n=1$; patient 15 ; Figure $3 B)$; (3) compression of the nondominant VA terminating in PICA at the C1-2 level during contraversive head rotation $(n=2$; patients 16 and 17 ; Figure $3 \mathrm{C})^{19}$; (4) compression of the dominant VA at the subaxial levels from the origin of VA to the C4 level during ipsi$(n=1$; patient 18$)$ or contraversive $(n=2$; patients 19 and 20$)$ head rotation (Figure 3D); or (5) compression of the dominant VA at the C1-2 level during ipsiversive head tilt $(n=1$; patient 21). ${ }^{16}$

Of the 24 VAs with a documented compression during head rotation or tilt, 19 (79.2\%) had compression at the C1-2 level during contraversive head rotation $(n=18)$ or ipsiversive head tilt $(n=1)$, whereas the remaining $5(20.8 \%)$ exhibited compression at the subaxial levels from the VA origin to the $\mathrm{C} 4$ level during ipsi- $(n=3)$ or contraversive $(n=2)$ head rotation.

There was no concurrent stenosis or anomaly (eg, hypoplasia or termination in the PICA) of VAs in 3 patients (patients 13, 14, and 15). Three patients (patients 15, 16, and 17) showed patent basilar artery flow through intact 1 VA when the other VA was compressed during head rotation.

Cervical CT disclosed osteophytes protruding into the foramen transversarium at the C6 level in 2 patients (patients 14 and 19), which may have compressed VA during head rotation.

\section{Oculographic Analyses of the Induced Nystagmus}

Twenty of $21(95.2 \%)$ patients developed nystagmus after head rotation or tilt with a latency of several seconds (Table 2). Eighteen of them (90\%) showed mixed downbeat, torsional, and horizontal nystagmus, whereas the remaining 2 (patients 6 and 17) had mixed downbeat and horizontal nystagmus. Downbeat component was most prominent in 15 patients $(83.3 \%)$, whereas horizontal one was conspicuous in 3. The intensities of horizontal and downbeat components were similar in the remaining 2 patients. The direction of horizontal and torsional components was same (ie, rightward and clockwise) in 17 patients $(94.4 \%)$, whereas 1 patient (patient 10) showed nystagmus beating leftward and clockwise with the head rotated to the right. After excluding 2 patients (patients 13 and 14) with bilateral VA compression during unilateral head rotation, 12 of 18 patients $(66.7 \%)$ exhibited horizontal and torsional nystagmus beating toward the compressed VA side. In contrast, 5 patients (patients 2, 6, 11, 12, and 17) showed horizontal and torsional nystagmus beating toward the intact VA side. The remaining patient (patient 10) had horizontal component beating toward the compressed VA, and torsional one beating toward the intact one.

Nine patients $(45.0 \%)$ exhibited reversal of the induced nystagmus even when the rotated head posture was maintained, and $10(47.6 \%)$ showed reversal of the nystagmus on resuming the neutral head position.

\section{Outcome}

After excluding 1 patient (patient 20) with a follow-up loss, all patients with conservative or surgical treatment did not develop posterior circulation stroke as a complication of RVAO during the median follow-up periods of 37.5 months (Table 1).

However, 1 (patient 1) patient experienced multiple embolic infarctions after mitral valve replacement and another (patient 6) had an infarction in the territory of middle cerebral artery, not related to RVAO. Four patients with conservative treatments $(21.1 \%$, patients $8,12,13$, and 19) showed resolution of symptoms during the follow-up.

\section{Discussion}

Our patients with RVAO developed vertigo when the head was rotated to 1 or both sides, or tilted to 1 side. Some patients also had associated tinnitus, fainting, or visual blurring. Dynamic angiography documented typical RVAO in $57.1 \%$ of patients. The remainders showed various patterns of RVAO, including compression of the VA at the subaxial levels, simultaneous 
Table 1. Clinical Features and Patterns of Vertebral Artery Compression

\begin{tabular}{|c|c|c|c|c|c|c|c|c|c|}
\hline Patient No. & Sex/Age & $\begin{array}{l}\text { Associated } \\
\text { Symptoms }\end{array}$ & $\begin{array}{l}\text { Provoking } \\
\text { Maneuver }\end{array}$ & $\begin{array}{l}\text { Compression } \\
\text { Side }\end{array}$ & $\begin{array}{c}\text { Compression } \\
\text { Level }\end{array}$ & $\begin{array}{c}\text { Baseline } \\
\text { Angiography }\end{array}$ & Treatment & F/U Period, mo & Outcome \\
\hline \multicolumn{10}{|c|}{ Typical RVAO } \\
\hline 1 & $\mathrm{M} / 56$ & $(-)$ & $\begin{array}{l}\text { Head rotation } \\
\quad \text { to } L\end{array}$ & $\mathrm{R}$ & C1-2 & L VA hypoplasia & Conservative & 37 & $\begin{array}{c}\text { Multiple embolic } \\
\text { infarctions after } \\
\text { MVR }\end{array}$ \\
\hline 2 & $\mathrm{M} / 56$ & Nausea & $\begin{array}{l}\text { Head rotation } \\
\quad \text { to } \mathrm{R}\end{array}$ & $\mathrm{L}$ & C1-2 & R VA hypoplasia & C1-2 fusion & 79 & No stroke \\
\hline 3 & $\mathrm{~F} / 70$ & $L$ tinnitus & $\begin{array}{l}\text { Head rotation } \\
\quad \text { to } \mathrm{R}\end{array}$ & L & C1-2 & $\begin{array}{l}\text { R distal VA } \\
\text { occlusion }\end{array}$ & Conservative & 67 & No stroke \\
\hline 4 & $\mathrm{M} / 56$ & B tinnitus & $\begin{array}{l}\text { Head rotation } \\
\quad \text { to } L\end{array}$ & $\mathrm{R}$ & C1-2 & L VA hypoplasia & Conservative & 7 & No stroke \\
\hline 5 & $\mathrm{~F} / 73$ & R tinnitus & $\begin{array}{l}\text { Head rotation } \\
\quad \text { to } L\end{array}$ & $\mathrm{R}$ & C1-2 & L VA hypoplasia & Conservative & 91 & No stroke \\
\hline 6 & $\mathrm{M} / 68$ & Fainting, nausea & $\begin{array}{l}\text { Head rotation } \\
\quad \text { to } R\end{array}$ & L & C1-2 & R VA hypoplasia & Conservative & 50 & MCA infarction \\
\hline 7 & $\mathrm{~F} / 55$ & $\begin{array}{l}\text { Fainting, } \\
\text { headache }\end{array}$ & $\begin{array}{l}\text { Head rotation } \\
\quad \text { to } L\end{array}$ & $\mathrm{R}$ & C1-2 & $\begin{array}{l}\text { L distal VA } \\
\text { occlusion }\end{array}$ & C1-2 fusion & 53 & No stroke \\
\hline 8 & $\mathrm{M} / 60$ & $(-)$ & $\begin{array}{l}\text { Head rotation } \\
\quad \text { to } R\end{array}$ & L & C1-2 & R VA hypoplasia & Conservative & 14 & $\begin{array}{l}\text { No stroke, } \\
\text { improved }\end{array}$ \\
\hline 9 & $\mathrm{M} / 73$ & $(-)$ & $\begin{array}{l}\text { Head rotation } \\
\quad \text { to } L\end{array}$ & $\mathrm{R}$ & C1-2 & L VA hypoplasia & Conservative & 87 & No stroke \\
\hline 10 & $\mathrm{~F} / 77$ & $\begin{array}{l}\text { Fainting, } \\
\text { vomiting }\end{array}$ & $\begin{array}{l}\text { Head rotation } \\
\quad \text { to } \mathrm{R}\end{array}$ & L & C1-2 & $\begin{array}{l}\text { R distal VA } \\
\text { occlusion }\end{array}$ & Conservative & 48 & No stroke \\
\hline 11 & $\mathrm{~F} / 77$ & $(-)$ & $\begin{array}{l}\text { Head rotation } \\
\quad \text { to } \mathrm{R}\end{array}$ & L & C1-2 & R VA occlusion & Conservative & 5 & No stroke \\
\hline 12 & $\mathrm{M} / 29$ & $(-)$ & $\begin{array}{l}\text { Head rotation } \\
\quad \text { to } L\end{array}$ & $\mathrm{R}$ & C1-2 & L VA occlusion & Conservative & 5 & $\begin{array}{l}\text { No stroke, } \\
\text { improved }\end{array}$ \\
\hline \multicolumn{10}{|c|}{ Atypical RVAO } \\
\hline 13 & $\mathrm{~F} / 56$ & $\begin{array}{l}\text { B tinnitus, } \\
\text { blurred vision }\end{array}$ & $\begin{array}{l}\text { Head rotation } \\
\quad \text { to } \mathrm{R}\end{array}$ & B & R C6/L C1-2 & Normal & Conservative & 38 & $\begin{array}{l}\text { No stroke, } \\
\text { improved }\end{array}$ \\
\hline 14 & $\mathrm{M} / 56$ & $(-)$ & $\begin{array}{l}\text { Head rotation } \\
\quad \text { to } L\end{array}$ & B & R C1-2/L C6 & Normal & Conservative & 18 & No stroke \\
\hline 15 & $\mathrm{M} / 37$ & $\begin{array}{l}\text { Fainting, blurred } \\
\text { vision }\end{array}$ & $\begin{array}{l}\text { Head rotation } \\
\text { to B }\end{array}$ & Each contra & C1-2 & Normal & Conservative & 13 & No stroke \\
\hline 16 & $\mathrm{M} / 59$ & Fainting & $\begin{array}{l}\text { Head rotation } \\
\quad \text { to } L\end{array}$ & $\mathrm{R}$ & C1-2 & $\begin{array}{l}\text { R VA terminating } \\
\text { in PICA }\end{array}$ & Conservative & 42 & No stroke \\
\hline 17 & $\mathrm{M} / 57$ & B tinnitus & $\begin{array}{l}\text { Head rotation } \\
\quad \text { to } R\end{array}$ & L & C1-2 & $\begin{array}{l}\text { L VA terminating } \\
\text { in PICA, }\end{array}$ & Conservative & 61 & No stroke, \\
\hline 18 & $\mathrm{~F} / 65$ & $\begin{array}{l}\mathrm{R} \text { tinnitus, } \\
\text { blurred vision }\end{array}$ & $\begin{array}{l}\text { Head rotation } \\
\quad \text { to } \mathrm{R}\end{array}$ & $\mathrm{L}$ & C4 & R VA hypoplasia & Conservative & 35 & No stroke \\
\hline 19 & $\mathrm{M} / 62$ & Vomiting & $\begin{array}{l}\text { Head rotation } \\
\quad \text { to } R\end{array}$ & $\mathrm{R}$ & C6 & L VA hypoplasia & Conservative & 22 & $\begin{array}{l}\text { No stroke, } \\
\text { improved }\end{array}$ \\
\hline 20 & $\mathrm{~F} / 61$ & R tinnitus & $\begin{array}{l}\text { Head rotation } \\
\quad \text { to } L\end{array}$ & $\mathrm{R}$ & VA origin & $\begin{array}{l}\text { L distal VA } \\
\text { occlusion }\end{array}$ & Conservative & F/U loss & $\begin{array}{l}\text { Loss of follow- } \\
\text { up }\end{array}$ \\
\hline 21 & $M / 29$ & $\begin{array}{l}\text { B tinnitus, } \\
\text { blurred vision }\end{array}$ & Head tilt to $\mathrm{L}$ & L & C1-2 & R VA hypoplasia & Conservative & 25 & No stroke \\
\hline
\end{tabular}

B indicates bilateral; C, cervical vertebra; F, female; L, left; M, male; MCA, middle cerebral artery; MVR, mitral valve replacement; PICA, posterior inferior cerebellar artery; R, right; and VA, vertebral artery.

compression of the bilateral VAs during unilateral head rotation, compression of the contralateral VA during head rotation to either side, compression of the ipsilateral VA during head rotation or tilt, and compression of the nondominant contralateral VA terminating in PICA during unilateral head rotation. We also found that the VAs were mostly compressed at the C1-2 atlantoaxial level during contralateral head rotation, whereas the remaining ones had compression at the subaxial region from the origin of VA to the C4 level during either either ipsilateral or contralateral head rotation. In only 2 patients, cervical CT documented osteophytes protruding into the foramen transversarium at the C6 level.

It has been recognized that mechanical compression of VA during head rotation is caused by muscular and tendinous 

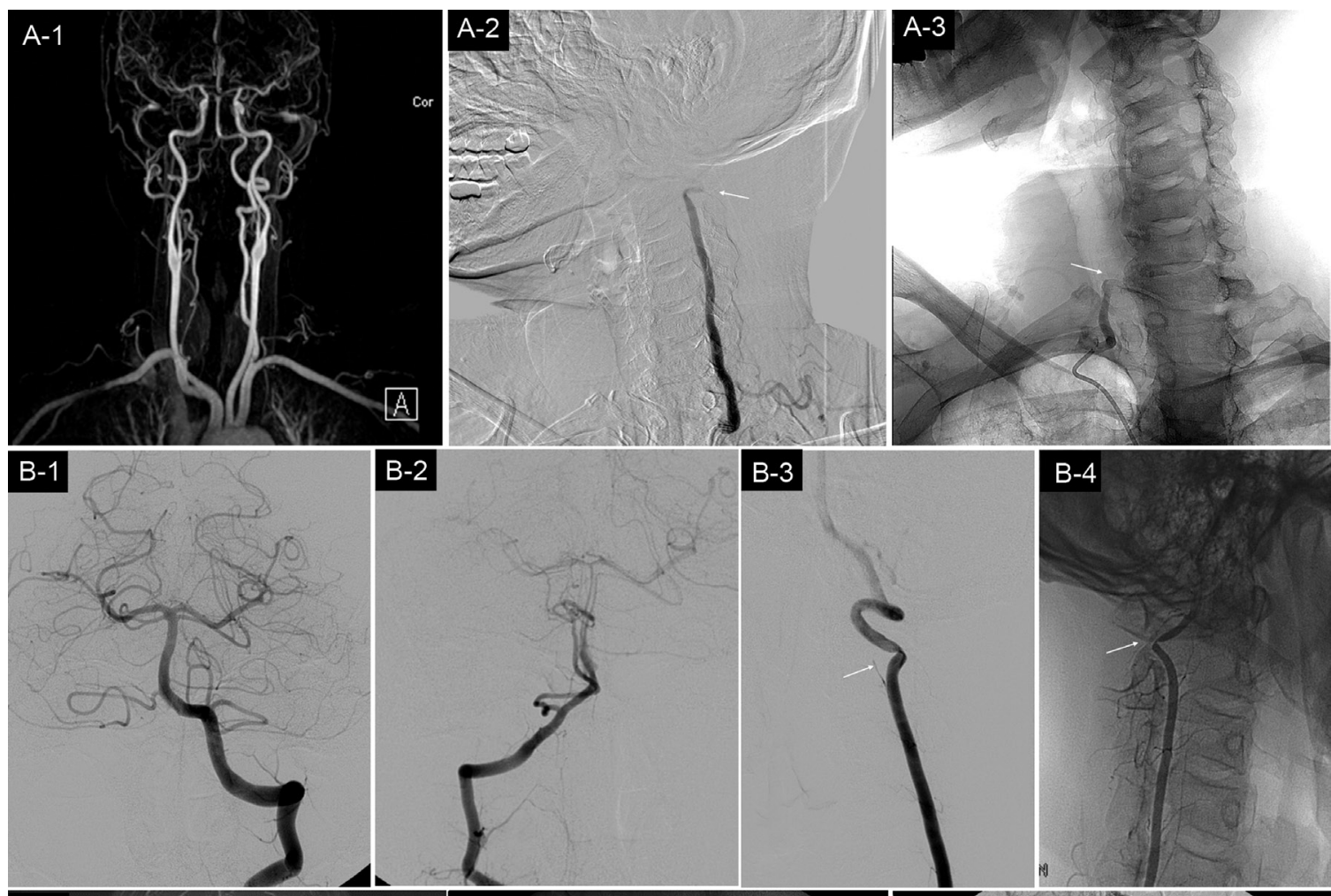

B-2

B-3
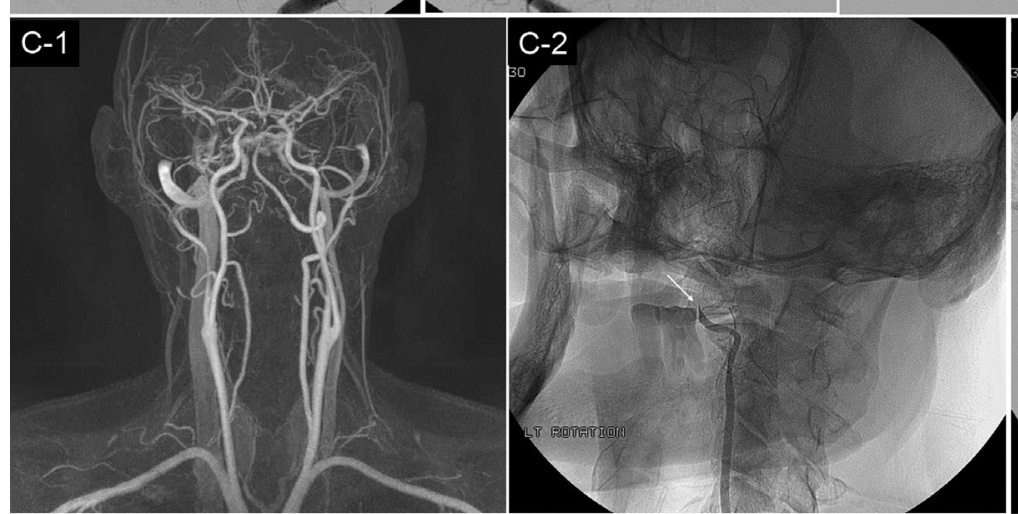

\section{D-1}
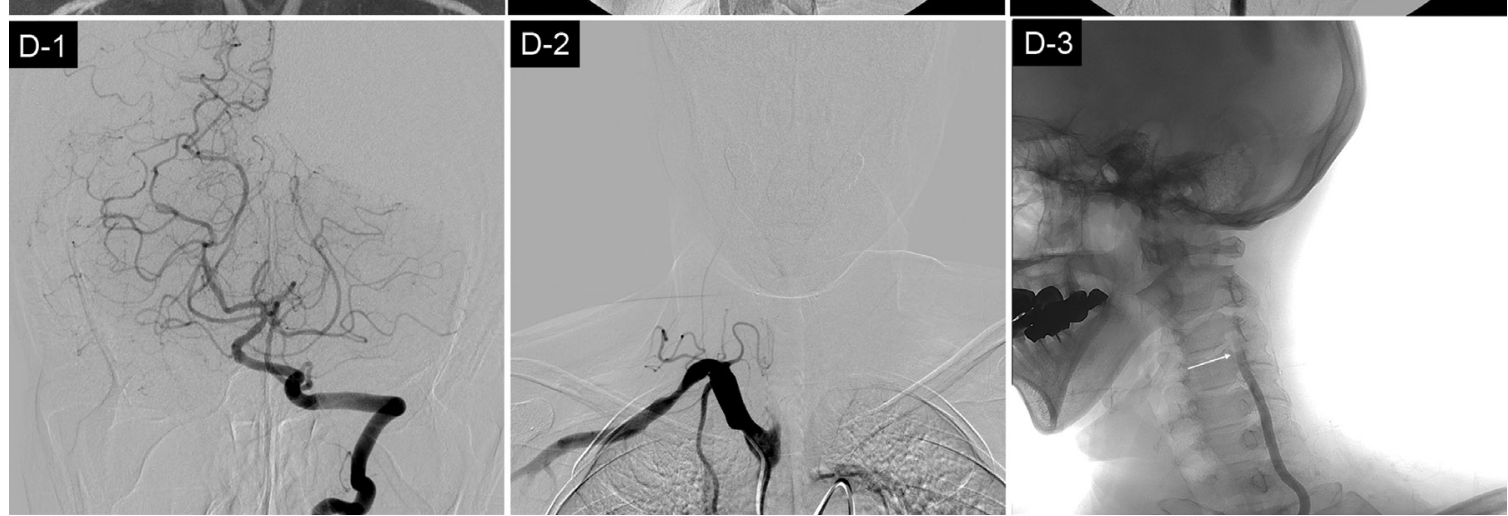

Figure 3. Magnetic resonance and dynamic angiography findings in patients with atypical patterns of rotational vertebral artery occlusion. A, In patient 13, MR angiography shows patent bilateral vertebral arteries (VAs; A-1). Dynamic angiography demonstrates simultaneous compression of the left VA at the C1-2 level (A-2) and the right VA at the C6 level (A-3) during rightward head rotation. B, In patient 15, cerebral angiography shows patent bilateral VAs (B-1 and B-2). Dynamic angiography discloses compression of the left VA during rightward head rotation (B-3) and compression of the right VA during leftward head rotation at the C1-2 level (B-4). C, In patient 16, MR angiography reveals a dominant left VA and a nondominant right VA terminating in posterior inferior cerebellar artery (C-1). Dynamic angiography exhibits compression of the nondominant right VA at the C1-2 level (C-2) and patent basilar artery flow through the left VA during leftward head rotation (C-3). D, In patient 19, cerebral angiography shows a patent left VA (D-1) and a complete occlusion of right VA at its origin from the subclavian artery (D-2). Dynamic angiography discloses compression of the left VA at the C4 level during rightward head rotation (D-3). 
Table 2. Patterns of Induced Nystagmus During Head Rotation or Tilt

\begin{tabular}{|c|c|c|c|c|c|}
\hline \multirow[b]{2}{*}{ Patient No. } & \multirow[b]{2}{*}{ Compression Side } & \multicolumn{4}{|c|}{ Nystagmus } \\
\hline & & Latency, s & Initial Direction & Reversal, Spontaneous & Reversal, Neutral \\
\hline 1 & $\mathrm{R}$ & 6 & $\mathrm{D}>R=\mathrm{CW}$ & No & Yes \\
\hline 2 & L & $4-5$ & $\mathrm{D}>R=\mathrm{CW}$ & Yes & Yes \\
\hline 3 & L & 3 & $\mathrm{D}>\mathrm{CCW}>\mathrm{L}$ & No & No \\
\hline 4 & $\mathrm{R}$ & $3-4$ & $\mathrm{D}>R>\mathrm{CW}$ & Yes & No \\
\hline 5 & $\mathrm{R}$ & 3 & $\mathrm{D}>\mathrm{CW}>\mathrm{R}$ & Yes & Yes \\
\hline 6 & L & $5-6$ & $D=R$ & No & No \\
\hline 7 & $\mathrm{R}$ & 7 & $\mathrm{D}>R=\mathrm{CW}$ & No & Yes \\
\hline 8 & L & 40 & $\mathrm{~L}>\mathrm{CCW}>\mathrm{D}$ & No & Yes \\
\hline 9 & $\mathrm{R}$ & 2 & $\mathrm{D}>R>\mathrm{CW}$ & Yes & No \\
\hline 10 & L & 5 & $\mathrm{D}>\mathrm{L}=\mathrm{CW}$ & Yes & Yes \\
\hline 11 & L & 5 & $\mathrm{D}>R=\mathrm{CW}$ & No & No \\
\hline 12 & $\mathrm{R}$ & 5 & $\mathrm{~L}=\mathrm{D}>\mathrm{CCW}$ & No & Yes \\
\hline 13 & B & 4 & $\mathrm{D}>\mathrm{L}=\mathrm{CCW}$ & No & Yes \\
\hline 14 & B & 7 & $\mathrm{D}>\mathrm{CCW}>\mathrm{L}$ & Yes & No \\
\hline 15 & Head rotation to either side & & & No nystagmus & \\
\hline 16 & $\mathrm{R}$ & 7 & $R>\mathrm{D}=\mathrm{CW}$ & $?$ & Yes \\
\hline 17 & L & 4 & $\mathrm{D}>\mathrm{R}$ & Yes & No \\
\hline 18 & L & 3 & $\mathrm{D}>\mathrm{L}=\mathrm{CCW}$ & No & No \\
\hline 19 & $\mathrm{R}$ & 7 & $\mathrm{D}>R=\mathrm{CW}$ & Yes & No \\
\hline 20 & $\mathrm{R}$ & $3-4$ & $R>D=C W$ & Yes & Yes \\
\hline 21 & L & 5 & $\mathrm{D}>\mathrm{L}=\mathrm{CCW}$ & No & No \\
\hline
\end{tabular}

B indicates bilateral; CCW, counterclockwise; CW, clockwise; D, downward; L, left; and R, right.

insertions, osteophytes, or degenerative changes resulting from cervical spondylosis, particularly at the atlantoaxial C1-2 level. ${ }^{2}$ The rotational obstruction of VA at the C1-2 level may also result from relative immobilization of the artery at the foramen transversarium at this level. ${ }^{4}$ During head rotation, the ipsiversive atlantoaxial joint is fixed, whereas the opposite atlas moves forward and downward in relation to the axis. This leads to kinking and stretching of the contralateral VA, resulting in significant decrease of the blood flow. ${ }^{4}$ This phenomenon has been shown with hemodynamic studies in cadavers or asymptomatic volunteers. ${ }^{28,29}$ Other extrinsic factors contributing to rotational occlusion at the C1-2 level include occipital bone anomaly, ${ }^{30}$ hypertrophy of the atlantooccipital membrane, ${ }^{31}$ tightness of the paravertebral muscles, ${ }^{32}$ and craniocervical junction anomaly. ${ }^{33}$ In some patients without detectable extrinsic causes, intraoperative exploration revealed constriction of the VA by fibrous bands, which are considered to develop from fibrous transformation of the neck muscles and cannot be easily documented by routine radiological evaluation. ${ }^{6,34}$ Three-dimensional CT angiography throughout head rotation may help to identify the surrounding structures and fibrous bands compressing the VA. ${ }^{17,32}$ At the subaxial level, the VA from the origin to its entrance into the foramen transversarium at $\mathrm{C} 6$ can be compressed by the anterior scalene and longus colli muscles, deep cervical fascia, and cervical sympathetic chain. ${ }^{2,6-9}$ When the VA passes through the foramina transversaria of the cervical vertebrae at C6-C2, it is susceptible to compression by osteophytes and other degenerative changes of cervical spondylosis., ${ }^{2,10-13}$ During head rotation toward the side of osterophytes, the ipsiversive VA may be compressed against the osteophytes, and the contraversive VA may be compressed at the foramina.

The analysis of nystagmus induced by head rotation or tilt may reflect mechanism of vertigo in RVAO.,10,16,19-22 Previously, on the basis of the mixed downbeat, and torsional and horizontal nystagmus beating toward the compressed VA, and accompanying tinnitus in the rotated head position, several reports have proposed transient ischemia and resulting excitation of the peripheral labyrinth as a possible mechanism of vertigo and nystagmus in RVAO.,.$^{3,20-22}$ The superior labyrinth supplied by the anterior labyrinthine artery is vulnerable to ischemia because of its small caliber and the lack of collaterals. ${ }^{35}$ Relative sparing of the inferior vestibular labyrinth in a patient with isolated internal auditory artery infarction provides a clinical support for this explanation. ${ }^{35}$ The prominent downbeat component of the induced nystagmus was ascribed to bilateral, but asymmetrical excitation of the anterior and horizontal semicircular canals in both sides. ${ }^{21,22}$ Spontaneous direction reversal of the nystagmus may be because of a transition from the initial ectopic discharges to a conduction block or to central adaptation. In accordance with these assumptions, oculographic analysis in our patients showed that most patients had prominent downbeat nystagmus mixed with torsional and horizontal components. The majority of the patients exhibited horizontal and torsional nystagmus beating toward the compressed VA side. About a half of the patients developed spontaneous reversal of the nystagmus even when the rotated head position was maintained and reversal of the 
nystagmus on resuming the neutral head position. However, in contrast to the earlier findings, ${ }^{16,20-22}$ the horizontal component was prominent, or the intensities of the horizontal and downbeat components were similar in some patients. Several patients also showed horizontal and torsional nystagmus beating toward the intact VA, and 1 patient exhibited directional dissociation of the horizontal and torsional components. Patients reported tinnitus either in the unilateral (the side of compressed VA or intact VA) or in the bilateral ears. These findings suggest that vertigo, nystagmus, and auditory symptoms in RVAO may be attributed to asymmetrical excitation or inhibition of the bilateral superior vestibular labyrinth and the cochlea because of ischemia.

Remarkably, 3 patients showed patent basilar artery flow through an intact VA when the other VA was compressed during head rotation, and 2 of them revealed a complete occlusion of the hypoplastic VA terminating in PICA. Because the basilar artery gave off both anterior inferior cerebellar arteries which usually supply the labyrinth, ${ }^{35}$ transient ischemia of the labyrinth seems implausible as a mechanism of nystagmus and vertigo in these patients. As the PICA usually supply the dorsolateral medulla and inferior cerebellum, the vertigo and nystagmus in these patients may be ascribed to transient ischemia of these structures. ${ }^{36}$ Two patients with an occlusion of the hypoplastic VA terminating in PICA developed different patterns of nystagmus. One patient showed prominent horizontal nystagmus mixed with downbeat and torsional components beating toward the compressed VA, whereas the other had mainly downbeat nystagmus with the horizontal component beating toward the intact VA. Patients with complete infarction in the lateral medulla commonly show mixed horizontal, vertical, and torsional nystagmus, but horizontal nystagmus may be ipsi- or contralesional, and the vertical components may be upbeat or downbeat. ${ }^{37}$ However, the prominent downbeat nystagmus in most patients with RVAO can be hardly explained by unilateral ischemia of the lateral medulla. Furthermore, absence of other neurological symptoms or signs does not support ischemia of the dorsolateral medulla in RVAO, although a greater vulnerability to ischemia of the vestibular nucleus than other brain stem structures has been suggested previously., ${ }^{3,20}$ During head rotation, decreased blood flow to the lower portion of the cerebellum supports transient ischemia of the inferior cerebellum in patients with RVAO. ${ }^{17,23,38}$ Inferior cerebellar infarction in the territory of PICA is a common cause of isolated vertigo, and the horizontal component of spontaneous nystagmus is mostly ipsilesional in unilateral PICA infarction. ${ }^{39}$ The downbeat and ipsiversive horizontal and torsional nystagmus may be explained by transient activation of the ipsiversive horizontal and anterior canal pathways because of disinhibition induced by ischemic insult to the flocculovestibular inhibitory pathways. ${ }^{40}$

On the basis of their safety, effectiveness, and good longterm outcome, surgical treatments, including cervical decompression or cervical spine fusion, have been recommended as the first line treatment option of RVAO..$^{2,23,25-27}$ Although cervical spine fusion provides complete relief of the symptoms and no reocclusion of the VA, most patients experience a significantly restricted range of head motion postoperatively, which restrains daily activities. ${ }^{23}$ However, cervical decompression does not limit physiological neck movements, but it has a problem of high reocclusion rate because of postoperative adhesion between the VA and the adjacent soft tissues. ${ }^{23,24}$ Another alternative is endovascular stent placement in the unaffected VA to increase the blood flow during head rotation. ${ }^{24}$ However, its efficacy and long-term outcome remain uncertain, and it cannot be performed in patients with occlusion or hypoplasia of the unaffected VA. To the best of our knowledge, there has been no systematic follow-up study on the long-term outcome of conservative treatments in RVAO. Only a previous review of published cases described that $\approx 50 \%$ of patients treated conservatively developed stroke with permanent neurological deficits. ${ }^{2,25-27}$ Our study showed a favorable long-term outcome of conservative treatments in RVAO. None of our patients with conservative treatments developed posterior circulation stroke, and 4 of them showed resolution of the symptoms during the follow-up, possibly because of spontaneous resolution of the extrinsic compression or central adaptation. Our results suggest that conservative treatments are safe and might be considered as a first-line treatment in RVAO.

\section{Acknowledgments}

We thank Mi-Jin Jung for the illustrations.

\section{Sources of Funding}

This work was supported by a grant of the Korean Heath Technology R\&D Project, Ministry of Health and Welfare, Republic of Korea (A070001)

\section{Disclosures}

None.

\section{References}

1. Tissington Tatlow WF, Bammer HG. Syndrome of vertebral artery compression. Neurology. 1957;7:331-340.

2. Kuether TA, Nesbit GM, Clark WM, Barnwell SL. Rotational vertebral artery occlusion: a mechanism of vertebrobasilar insufficiency. Neurosurgery. 1997;41:427-432; discussion 432.

3. Strupp M, Planck JH, Arbusow V, Steiger HJ, Brückmann H, Brandt T. Rotational vertebral artery occlusion syndrome with vertigo due to "labyrinthine excitation". Neurology. 2000;54:1376-1379.

4. Barton JW, Margolis MT. Rotational obstructions of the vertebral artery at the atlantoaxial joint. Neuroradiology. 1975;9:117-120.

5. Yang PJ, Latack JT, Gabrielsen TO, Knake JE, Gebarski SS, Chandler WF. Rotational vertebral artery occlusion at C1-C2. Am J Neuroradiol. 1985;6:96-100

6. Mapstone T, Spetzler RF. Vertebrobasilar insufficiency secondary to vertebral artery occlusion froma fibrous band. Case report. J Neurosurg. 1982;56:581-583.

7. Kojima N, Tamaki N, Fujita K, Matsumoto S. Vertebral artery occlusion at the narrowed "scalenovertebral angle": mechanical vertebral occlusion in the distal first portion. Neurosurgery. 1985;16:672-674.

8. Fujimoto S, Terai Y, Itoh T. Rotational stenosis of the first segment of the vertebral artery through compression by the cervical sympathetic chaincase report. Neurol Med Chir (Tokyo). 1988;28:1020-1023.

9. Dadsetan MR, Skerhut HE. Rotational vertebrobasilar insufficiency secondary to vertebral artery occlusion from fibrous band of the longus coli muscle. Neuroradiology. 1990;32:514-515.

10. Rosengart A, Hedges TR 3rd, Teal PA, DeWitt LD, Wu JK, Wolpert S, et al. Intermittent downbeat nystagmus due to vertebral artery compression. Neurology. 1993;43:216-218.

11. Bulsara KR, Velez DA, Villavicencio A. Rotational vertebral artery insufficiency resulting from cervical spondylosis: case report and review of the literature. Surg Neurol. 2006;65:625-627. 
12. Kawaguchi T, Fujita S, Hosoda K, Shibata Y, Iwakura M, Tamaki N. Rotational occlusion of the vertebral artery caused by transverse process hyperrotation and unilateral apophyseal joint subluxation. Case report. $J$ Neurosurg. 1997;86:1031-1035.

13. Vates GE, Wang KC, Bonovich D, Dowd CF, Lawton MT. Bow hunter stroke caused by cervical disc herniation. Case report. J Neurosurg. 2002;96(1 Suppl):90-93.

14. Dabus G, Gerstle RJ, Parsons M, Cross DT 3rd, Moran CJ, Thompson R, et al. Rotational vertebrobasilar insufficiency due to dynamic compression of the dominant vertebral artery by the thyroid cartilage and occlusion of the contralateral vertebral artery at C1-2 level. J Neuroimaging. 2008;18:184-187.

15. Tsutsumi S, Ito M, Yasumoto Y. Simultaneous bilateral vertebral artery occlusion in the lower cervical spine manifesting as bow hunter's syndrome. Neurol Med Chir (Tokyo). 2008;48:90-94.

16. Choi JH, Kim MJ, Lee TH, Moon IS, Choi KD, Kim JS. Dominant vertebral artery occlusion during ipsilateral head tilt. Neurology. 2011;76:1679.

17. Matsuyama T, Morimoto T, Sakaki T. Bow Hunter's stroke caused by a nondominant vertebral artery occlusion: case report. Neurosurgery. 1997;41:1393-1395.

18. Yeh JF, Lin YJ, Po HL, Wang SF, Pan PY, Cheng SJ, et al. A case of bow hunter's stroke caused by non-dominant vertebral artery. Acta Neurol Taiwan. 2005;14:69-73.

19. Noh Y, Kwon OK, Kim HJ, Kim JS. Rotational vertebral artery syndrome due to compression of nondominant vertebral artery terminating in posterior inferior cerebellar artery. J Neurol. 2011;258:1775-1780.

20. Choi KD, Shin HY, Kim JS, Kim SH, Kwon OK, Koo JW, et al. Rotational vertebral artery syndrome: oculographic analysis of nystagmus. Neurology. 2005;65:1287-1290.

21. Marti S, Hegemann S, von Büdingen HC, Baumgartner RW, Straumann D. Rotational vertebral artery syndrome: 3D kinematics of nystagmus suggest bilateral labyrinthine dysfunction. J Neurol. 2008;255:663-667.

22. Kim HA, Yi HA, Lee CY, Lee H. Origin of isolated vertigo in rotational vertebral artery syndrome. Neurol Sci. 2011;32:1203-1207.

23. Matsuyama T, Morimoto T, Sakaki T. Comparison of C1-2 posterior fusion and decompression of the vertebral artery in the treatment of bow hunter's stroke. J Neurosurg. 1997;86:619-623.

24. Sugiu K, Agari T, Tokunaga K, Nishida A, Date I. Endovascular treatment for bow hunter's syndrome: case report. Minim Invasive Neurosurg. 2009;52:193-195.

25. Vilela MD, Goodkin R, Lundin DA, Newell DW. Rotational vertebrobasilar ischemia: hemodynamic assessment and surgical treatment. Neurosurgery. 2005;56:36-43; discussion 43.
26. Lu DC, Zador Z, Mummaneni PV, Lawton MT. Rotational vertebral artery occlusion-series of 9 cases. Neurosurgery. 2010;67:1066-1072; discussion 1072 .

27. Cornelius JF, George B, N'dri Oka D, Spiriev T, Steiger HJ, Hänggi D. Bow-hunter's syndrome caused by dynamic vertebral artery stenosis at the cranio-cervical junction-a management algorithm based on a systematic review and a clinical series. Neurosurg Rev. 2012;35:127-135; discussion 135.

28. Faris AA, Poser CM, Wilmore DW, Agnew CH. Radiologic visualization of neck vessels in healthy men. Neurology. 1963;13:386-396.

29. Toole JF, Tucker SH. Influence of head position upon cerebral circulation. Studies on blood flow in cadavers. Arch Neurol. 1960;2:616-623.

30. Tominaga T, Takahashi T, Shimizu H, Yoshimoto T. Rotational vertebral artery occlusion from occipital bone anomaly: a rare cause of embolic stroke. Case report. J Neurosurg. 2002;97:1456-1459.

31. Akar Z, Kafadar AM, Tanriover N, Dashti RS, Islak C, Kocer N, et al. Rotational compression of the vertebral artery at the point of dural penetration. Case report. J Neurosurg. 2000;93(2 Suppl):300-303.

32. Wakayama K, Murakami M, Suzuki M, Ono S, Shimizu N. Ischemic symptoms induced by occlusion of the unilateral vertebral artery with head rotation together with contralateral vertebral artery dissection-case report. J Neurol Sci. 2005;236:87-90.

33. Puca A, Scogna A, Rollo M. Craniovertebral junction malformation and rotational occlusion of the vertebral artery. Br J Neurosurg. 2000;14:361-364.

34. Hanakita J, Miyake H, Nagayasu S, Nishi S, Suzuki T. Angiographic examination and surgical treatment of bow hunter's stroke. Neurosurgery. 1988;23:228-232.

35. Kim JS, Lopez I, DiPatre PL, Liu F, Ishiyama A, Baloh RW. Internal auditory artery infarction: clinicopathologic correlation. Neurology. 1999;52:40-44.

36. Tatu L, Moulin T, Bogousslavsky J, Duvernoy H. Arterial territories of human brain: brainstem and cerebellum. Neurology. 1996;47:1125-1135.

37. Choi KD, Oh SY, Park SH, Kim JH, Koo JW, Kim JS. Head-shaking nystagmus in lateral medullary infarction: patterns and possible mechanisms. Neurology. 2007;68:1337-1344.

38. Sakaguchi M, Kitagawa K, Hougaku H, Hashimoto H, Nagai Y, Yamagami H, et al. Mechanical compression of the extracranial vertebral artery during neck rotation. Neurology. 2003;61:845-847.

39. Huh YE, Kim JS. Patterns of spontaneous and head-shaking nystagmus in cerebellar infarction: imaging correlations. Brain. 2011;134 (Pt 12):3662-3671.

40. Ito M, Nisimaru N, Yamamoto M. Specific patterns of neuronal connexions involved in the control of the rabbit's vestibulo-ocular reflexes by the cerebellar flocculus. J Physiol. 1977;265:833-854. 


\section{Stroke}

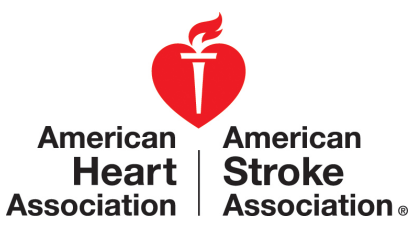

Rotational Vertebral Artery Occlusion: Mechanisms and Long-term Outcome Kwang-Dong Choi, Jae-Hwan Choi, Ji-Soo Kim, Hyo Jung Kim, Min-Ji Kim, Tae-Hong Lee, Hyung Lee, In Soo Moon, Hui Jong Oh and Jae-Il Kim

Stroke. 2013;44:1817-1824; originally published online May 21, 2013; doi: 10.1161/STROKEAHA.113.001219

Stroke is published by the American Heart Association, 7272 Greenville Avenue, Dallas, TX 75231

Copyright (c) 2013 American Heart Association, Inc. All rights reserved.

Print ISSN: 0039-2499. Online ISSN: 1524-4628

The online version of this article, along with updated information and services, is located on the World Wide Web at:

http://stroke.ahajournals.org/content/44/7/1817

\footnotetext{
Permissions: Requests for permissions to reproduce figures, tables, or portions of articles originally published in Stroke can be obtained via RightsLink, a service of the Copyright Clearance Center, not the Editorial Office. Once the online version of the published article for which permission is being requested is located, click Request Permissions in the middle column of the Web page under Services. Further information about this process is available in the Permissions and Rights Question and Answer document.
}

Reprints: Information about reprints can be found online at: http://www.lww.com/reprints

Subscriptions: Information about subscribing to Stroke is online at: http://stroke.ahajournals.org//subscriptions/ 